\title{
Spatial location of first- and second-order visual conditioned stimuli in second-order conditioning of the pigeon's keypeck
}

\author{
BEVERLY S. MARSHALL, DANIEL S. GOKEY, PATRICIA L. GREEN \\ and MICHAEL E. RASHOTTE \\ Florida State University, Tallahassee, Florida 32306
}

\begin{abstract}
A keylight (S1) always projected on one response key signaled food for hungry pigeons in a first-order classical conditioning procedure. When S1 evoked strong keypecking, it was presented without food on some of the trials that were signaled by other keylights (S2) in a second-order conditioning procedure. On half the second-order trials, the occurrence of $\mathrm{S} 1$ was signaled by an S2 projected on the same response key as S1; on the remaining trials, S1 was signaled by another S2 projected on a different key than S1. Acquisition of keypecking to S2 was faster when S2 and S1 occurred on the same response key than when they occurred on different keys. Asymptotic responding to the two S2s was not different, however. A control group showed that keypecking to S2 on the "different" key resulted from the pairing of S2 on that key with S1 on the other key. The enhancement of acquisition to S2 when it occurs in the same location as S1 may reflect the effects of stimulus similarity on conditioning, or, simply, a more optimal temporal relationship between S2 and S1. The fact that directed motor behavior can be established to a stimulus in one location solely through pairing of that stimulus with a well-conditioned stimulus in another location further implicates second-order conditioning as a factor in conditioned reinforcement effects in instrumental training.
\end{abstract}

Several experiments have demonstrated that pigeons will learn to peck a visual stimulus projected on a response key (S2) when that stimulus signals another stimulus (S1) that has previously been paired with food (Leyland, 1977; Patterson \& Winokur, 1973; Rashotte, Griffin, \& Sisk, 1977; Rescorla \& Furrow, 1977, Experiment 3; Zentall \& Hogan, 1975; Green \& Schweitzer, Note 1; Marshall \& Rashotte, Note 2). At least some of these demonstrations constitute clear evidence of second-order conditioning (Pavlov, 1927) because they show that pecking to $\mathrm{S} 2$ is established and/or maintained only when S2 and S1 are paired and when S1 has had a history of being paired with food (Leyland, 1977; Rashotte et al., 1977).

In the experiments conducted to date, pecking was established to S2 when S1 was (1) another visual stimulus projected on a response key, (2) an auditory stimulus, (3) an overhead houselight, (4) the sight of inaccessible food, or (5) an auditory stimulus that controlled keypecking through discriminative operant training. The experiment reported here investigated

This research was supported in part by Grant BNS 77-16844 from the National Science Foundation, M. E. Rashotte, principal investigator, and National Institute of Mental Health Training Grant MH-11218. The authors wish to thank Kenneth Grosslight for assistance in collection of the data, and Jeffrey O'Connell for helpful comments on an earlier draft of this paper. Requests for reprints should be sent to Michael E. Rashotte, Department of Psychology, Florida State University, Tallahassee, Florida 32306. second-order conditioning when S2 and S1 were different keylights. The question of major interest was whether the development of keypecking to S2 is influenced by the spatial locations of the two keylights. This experimental manipulation is pertinent to the proposal that stimulus similarity is a variable that influences the formation of associations in classical conditioning (Rescorla \& Furrow, 1977; Testa, 1975). One implication of this proposal is that when S2 and S1 occur in the same spatial location, responding will be acquired more readily than when they occur in different locations. In all but one of the experiments conducted to date with keylights as S2 and S1, both stimuli have been presented successively on a single key. The exception is an experiment by Green and Schweitzer (Note 1) that demonstrated that keypecking can be established to S2 when S2 and S1 occur on separate keys. The present experiment used a within-subjects design to compare the acquisition of responding to two S2s that occurred on the same key as, or on a different key than, the one on which S1 was presented. It also included a control group that assessed the role of generalized keypecking from stimuli on the "same" key to $\mathrm{S} 2$ on the "different" key.

\section{METHOD} Subjects
Sixteen experimentally naive White Carneaux pigeons were
maintained at $80 \%$ of their free-feeding weights. Subjects were 
housed individually under constant illumination with water and grit continuously available.

\section{Apparatus}

Training was conducted in three identical chambers, each measuring $40 \times 37.5 \times 39.4 \mathrm{~cm}$. The interior of each chamber was painted flat black. Two response keys and an opening to a grain hopper were located on one wall of each chamber. The keys were $2.5 \mathrm{~cm}$ in diameter, $12.8 \mathrm{~cm}$ apart, and $25.4 \mathrm{~cm}$ above the grid floor. The $5.5 \times 5.0 \mathrm{~cm}$ opening to the hopper was centered between the keys, and its lower edge was $10.2 \mathrm{~cm}$ above the floor. A minimum force of $.28 \mathrm{~N}(28 \mathrm{~g})$ was required to operate the microswitches on the keys. The keys could be transilluminated with a white or blue light, or with a white vertical line on a red background, by applying $28-\mathrm{V}$ ac to 1820 bulbs in in-line projectors. Access to mixed grain was controlled by raising the hopper to the opening in each chamber for a fixed duration. The opening was illuminated by a recessed white bulb while the hopper was raised. Throughout sessions, each chamber was illuminated by a $110-\mathrm{V}$ ac $25-\mathrm{W}$ frosted incandescent bulb mounted in a translucent plastic housing in the rear corner of the ceiling. Extraneous sounds were masked by white noise delivered through a speaker in each chamber. The behavior of the animals was monitored by closed-circuit television cameras mounted in the ceiling of the chambers. Television monitors and electromechanical control and recording equipment were located in a room adjacent to the test chambers.

\section{Procedure}

First-order conditioning. After two sessions of magazine training, all pigeons received 20 consecutive sessions in which a 6-sec white keylight (S1) was paired with 4-sec access to grain. On the 30 trials in each session, S1 was always presented on the left key and was followed immediately by grain. The intertrial interval (ITI) was $120 \mathrm{sec}$. The right key was not lighted during these sessions and was covered with black tape.

Second-order conditioning. Beginning in Session 21, secondorder conditioning sessions alternated daily with first-order sessions. Each of the 10 trials in a second-order session consisted of presentation of a 6-sec visual stimulus (S2) and, depending on the phase of the experiment and the group assignment, was followed either by no further visual stimulus or by S1. The ITI remained at $120 \mathrm{sec}$. The pigeons were exposed to two different stimuli as $\mathrm{S} 2$ in each session. On a random half of the trials, one visual stimulus was presented as $\mathrm{S} 2$ on the left key and, on the remaining trials, a different visual stimulus was presented as $\mathbf{S 2}$ on the right key. The stimulus on the left key was designated as S2-S to indicate that it occurred on the same key where $\mathrm{S} 1$ was presented. The stimulus on the right key was designated S2-D. For half of the animals in each group, S2-S was a blue keylight and S2-D was a white vertical line on a red background. These stimuli were reversed for the other half of the animals.

In the initial second-order sessions, only the $\mathrm{S} 2$ stimuli were presented to allow generalized keypecking to subside. These sessions continued for each bird until two successive sessions were completed with $10 \%$ or fewer trials with a key contact or a "rated" peck. During a trial, observers watching the television monitors scored the trial as being one with a rated peck if the pigeon thrust its head forward toward the lighted key and then retracted it to approximately the starting position at least once. A trial with a rated peck was scored regardless of whether the pecking movement resulted in a key switch closure, and there was virtually perfect scoring reliability between the multiple observers.

After subjects met the criterion of no pecking to the S2 stimuli, an experimental and a control group were formed with 10 and 6 subjects, respectively, and S2/S1 pairings began. In each second-order session, all subjects received 106 -sec presentations of S1 on the left key with an ITI of $120 \mathrm{sec}$. For the experimental group, a random half of these S1 presentations was preceded by presentation of S2-S, and the other half by S2-D. The control group received S2-S trials identical to the experimental group, but the five presentations of S2-D occurred randomly with respect to the remaining five $S 1$ presentations. S2-D presentations were programmed on a VT 240 -sec schedule with the restriction that S2-S and S2-D could not be presented simultaneously. The control group allows the contribution of generalized pecking from S2-S to S2-D to be assessed. Four sessions were given in which $\mathrm{S} 2 / \mathrm{S} 1$ pairings were possible. Throughout second-order conditioning sessions, grain was never presented. At no time in the experiment did keypecks have any programmed consequences.

\section{RESULTS}

Keypecking to $\mathrm{S} 1$ was established in all pigeons during first-order conditioning sessions. In Session 20, the experimental and control groups contacted S1 on a median of $100 \%$ and $88.5 \%$ of the trials, respectively, at median rates of 74.33 and 53.17 responses/min. One subject in the control group rarely contacted the key but was observed to make pecking movements directed toward the key on every trial. A median of 5 (range: 3-10) sessions in which $S 2$ was presented alone was required to reduce generalized pecking to the two $S 2$ stimuli so that $\mathrm{S} 2 / \mathrm{S} 1$ pairings could begin.

During the subsequent second-order sessions, when S2 and S1 were paired, three pigeons never responded to either S2-S or S2-D on three of four successive trials. One pigeon was in the experimental group and two were

Table 1

Number of Presentations of S2-S and S2-D Prior to Reaching an Acquisition Criterion of Three Out of Four Successive Trials of Each Type With a Key Contact or a Rated Peck

\begin{tabular}{lrrrr} 
& \multicolumn{2}{c}{ Key Contact } & \multicolumn{2}{c}{ Rated Peck } \\
\cline { 2 - 3 } \cline { 5 - 5 } Pigeon & S2-S & S2-D & S2-S & S2-D \\
\hline & \multicolumn{4}{c}{ Experimental Group } \\
P6811 & 2 & 7 & 1 & 4 \\
P6452* & 2 & 4 & 2 & 2 \\
P6501* & 3 & 13 & 1 & 11 \\
P10125* & 4 & 9 & 3 & 8 \\
P5640 & 4 & 10 & 2 & 8 \\
P6519 & 5 & 15 & 3 & 0 \\
P6427 & 5 & 7 & 5 & 7 \\
P5359 & 6 & $>20$ & 5 & 20 \\
P4758* & 10 & 9 & 4 & 8 \\
Median & 4 & 9 & 3 & 8 \\
& \multicolumn{4}{c}{ Control Group } \\
P420* & 2 & $>20$ & 2 & $>20$ \\
P701* & 5 & $>20$ & 0 & $>20$ \\
P715 & 7 & $>20$ & 6 & $>20$ \\
P704 & $>20$ & $>20$ & 8 & $>20$ \\
Median & 6 & $>20$ & 4 & $>20$ \\
\hline
\end{tabular}

Note-Data are shown for individual animals in the experimental and control groups. $\quad$ *Pigeons trained with the blue color as S2-S. For these pigeons, S2-D was a vertical white line on a red background. The stimuli were reversed for the other pigeons. All pigeons had a white keylight as $S 1$. 
in the control group. These pigeons are excluded from further considerations, since they failed to show evidence of sustained second-order conditioning. Table 1 summarizes the acquisition of responding to S2-S and S2-D for the remaining subjects in each group. The median number of pairings of S2-S with S1, before a criterion of three out of four successive S2-S presentations with a response was reached, was very similar for the experimental and control groups and did not differ reliably in the key-contact or rated-peck measures (Wilcoxon rank sum test, Ws $\leqslant 34$, ps $>.05$ ). However, within each group, responding was acquired faster to S2-S than to S2-D (Wilcoxon signed-rank test, experimental $\mathrm{T}^{+} \mathrm{s} \leqslant 3.5$, ps $<.05$; control $\mathrm{T}^{+} \mathrm{s}=0$, ps $\left.=.062\right) .{ }^{1}$ In fact, the control group showed no acquisition of keypecking to S2-D, which was never paired with S1. Examination of the individual animal data in Table 1 indicates that the ease of conditioning S2 was not related to whether $S 2$ and $S 1$ were both colors or were a color and a line orientation (cf. Rescorla \& Furrow, 1977).

Figure 1 shows a session-by-session plot of the median percent of trials with a response to S2-S and S2-D for each group and for the two response measures. In both groups, responding to S2-S was established

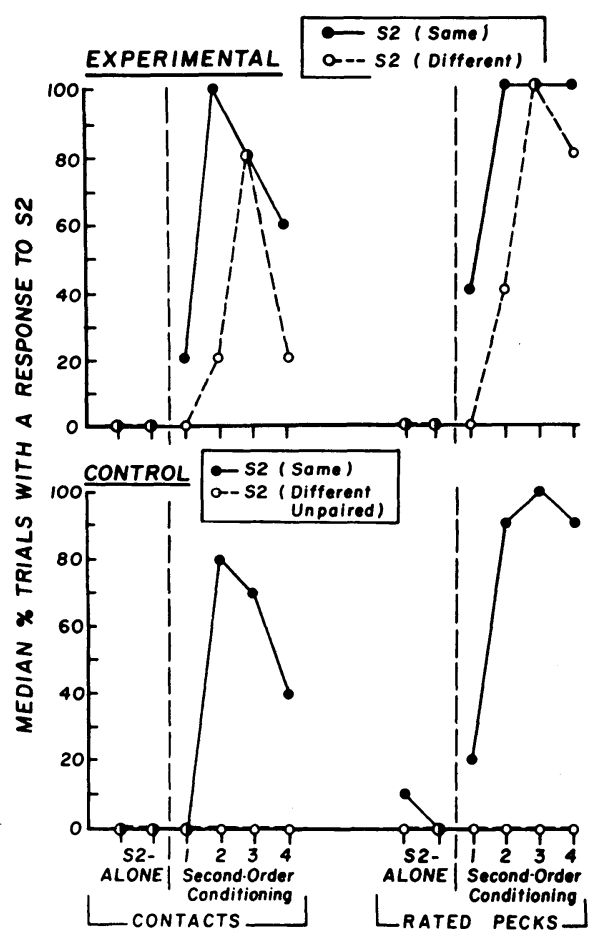

Figure 1. Median percent of trials with a key contact (left panels) or rated pecking movement (right panels) toward S2-S and S2-D in second-order conditioning sessions. The top panels show responding by the experimental group, the bottom panels show responding by the control group. The data points labeled S2-alone on the abscissa are for the last two sessions in which the S2 stimuli were presented alone to reduce generalized keypecking from first-order conditioning. sooner than to S2-D, but across second-order conditioning sessions, the difference in keypecking to the two stimuli narrowed for the experimental group. On the last second-order conditioning session for both response measures, there was no difference in responding to the two stimuli in the experimental group (Wilcoxon signedrank test, $\mathrm{T}^{+} \mathrm{s} \geqslant 10$, ps $>.05$ ). The figure also shows that, in the control group, keypecking did not develop to S2-D. Between-groups comparisons in the final second-order session indicated no significant differences in either response measure to S2-S (Wilcoxon rank sum test, Ws $\leqslant 38$, ps $>.05$ ), but the two groups differed on both response measures to S2-D (Wilcoxon rank sum test, $W s \geqslant 46$, ps $\leqslant .01$ ).

Subjects in both groups continued to peck S1 throughout second-order conditioning sessions. In the final session, the median percent of trials with a key contact to S1 was $80 \%$ following S2-S and $80 \%$ following S2-D for the experimental group, and $60 \%$ and $70 \%$, respectively, for the control group. The median percent of trials with a rated peck to S1 during the same session was $100 \%$ following both S2s for each group.

\section{DISCUSSION}

In the experimental group, keypecking was acquired more readily to $S 2$ when $S 2$ and $S 1$ were presented on the same response key than when they occurred on different keys. By the time second-order conditioning sessions were terminated, however, responding to S2 was not related to stimulus location. The control group's data indicate that the responding to S2-D by the experimental group is not attributable to generalization from S2-S or from S1, both of which controlled keypecking on the other key. Instead, responding to S2-D required pairings with $\mathrm{S} 1$, which is a necessary condition for second-order conditioning to be claimed. Taken together, these results indicate that second-order conditioning of the pigeon's keypeck is more easily achieved when the two visual stimuli serving as S2 and S1 occur in the same spatial location than when they occur in different locations. It should be noted, however, that S2-S/S1 pairings were given on the key where S1/US pairings occurred in first-order sessions. This may have enhanced the facilitating effects of the "same" location. It remains to be determined whether the present results would be obtained if S1 always occurred on a different key in first- and second-order sessions.

The present findings are consistent with previous evidence that stimulus similarity is a determinant of second-order conditioning (Rescorla \& Furrow, 1977). In the present case, similarity in spatial location of S2 and S1 produced more rapid second-order conditioning than when the stimuli were in different locations. Other interpretations of the data are also plausible. In particular, acquisition of responding to S2-S may be faster because a pigeon that has oriented toward S2-S will be exposed to S1 immediately following the offset of S2. On S2-D trials, the pigeon would have to reorient from S2 to another spatial location to be fully stimulated by $S 1$. The net result might be a longer and more variable delay between offset of S2-D and stimulation by S1, which might slow acquisition of responding to S2-D relative to S2-S. If this were the case, the subsequent narrowing of the difference in responding to S2-S and S2-D in the experimental group might come from a reduction in the S2-D/S1 delay as training progresses. This would occur if the pigeons became more proficient in anticipating the occurrence of S1 on the left key during presentation of an S2 
on the right key. In fact, informal observations indicated that in second-order conditioning, several pigeons in the experimental group began to move toward the unlighted left key (where S1 was to be presented) during the last $1 \mathrm{sec}$ or so that S2-D was present.

It may be noted that a temporal delay between of fset of S2 and onset of S1 has been claimed to enhance second-order conditioning (Pavlov, 1927) rather than to retard it, as proposed above. Pavlov's claim was made on the basis of results in the salivary conditioning preparation, however, and recent experiments with other response systems do not support his claim as the general case (Maisiak \& Frey, 1977; Rescorla, 1973). Unfortunately, as yet, there has been no parametric investigation of the S2/S1 interstimulus interval in the autoshaping preparation.

Finally, Rashotte et al. (1977) pointed out that, because directed motor action is susceptible to second-order conditioning, at least some of the effects attributed to conditioned reinforcers in instrumental conditioning may arise from this process. That is, the contingency between an instrumental response and presentation of a first-order CS that characterizes the conditioned reinforcement procedure includes an embedded second-order conditioning contingency in which the stimuli present when the response is performed act as S2, and the response-produced CS acts as S1. When the response is directed toward a localized stimulus (as when a key must be pecked, a lever pressed, or the arm of a maze entered), that stimulus (S2) may come to control directed motor behavior because it has stimulated the animal immediately before each (response-produced) presentation of $\mathrm{S} 1$. If the directed motor action that results from this implicit S2/S1 contingency is compatible with the topography of the instrumental response, performance will be facilitated and the effects of the conditioned reinforcer will appear to be strong. Moore (1973) employed similar logic to show how first-order conditioning of directed motor action might contribute to the instrumental performance maintained by primary (unconditioned) reinforcers. While there are important reasons for doubting that motor actions evoked by first- or second-order classically conditioned stimuli can account for all the nuances of instrumental performance (e.g., Moore, 1973; Rashotte, 1979), it seems likely that they contribute to performance in some settings. The present results implicate second-order conditioning as a viable influence in conditioned reinforcement experiments where an instrumental response is performed in one location and the conditioned reinforcer is presented in another.

\section{REFERENCE NOTES}

1. Green, L., \& Schweitzer, L. Second-order conditioning of the pigeon's keypeck using an autoshaping procedure. Paper presented at the 17th Annual Meeting of the Psychonomic Society, St. Louis, 1976.
2. Marshall, B. S., \& Rashotte, M. E. Partial reinforcement in second-order conditioning of the pigeon's keypeck. Paper presented at the 49th Annual Meeting of the Midwestern Psychological Association, Chicago, 1977.

\section{REFERENCES}

LEYLAND, C. M. Higher-order autoshaping. Quarterly Journal of Experimental Psychology, 1977, 29, 607-619.

MaIsiaK, R., \& FreY, P. W. Second-order conditioning: The importance of stimulus overlap on second-order trials. Animal Learning \& Behavior, 1977, 5, 309-314.

Moore, B. R. The role of directed Pavlovian reactions in simple instrumental learning in the pigeon. In R. A. Hinde \& J. Stevenson-Hinde (Eds.), Constraints on learning. London: Academic Press, 1973.

Patterson, D. D., \& Winokur, S. Autoshaping pigeons' keypecking with a conditioned reinforcer. Bulletin of the Psychonomic Society, 1973, 1, 247-249.

Pavlov, I. P. Conditioned reflexes (G. V. Anrep, trans.). London: Oxford University Press, 1927.

RAshotte, M. E. Reward training: Methods and data. In M. E. Bitterman, V. M. LoLordo, J. B. Overmier, \& M. E. Rashotte, Animal Learning: Survey \& Analysis. New York: Plenum Press, 1979.

Rashotte, M. E., Griffin, R. W., \& Sisk, C. L. Second-order conditioning of the pigeon's keypeck. Animal Learning \& Behavior, 1977, 5, 25-38.

REsCoRLA, R. A. Second-order conditioning: Implications for theories of learning. In F. J. McGuigan \& D. B. Lumsden (Eds.), Contemporary approaches to conditioning and learning. Washington, D.C: Winston, 1973.

Rescorla, R. A., \& FURROw, D. R. Stimulus similarity as a determinant of Pavlovian conditioning. Journal of Experimental Psychology: Animal Behavior Processes, 1977, 3, 203-215.

Testa, T. J. Effects of similarity of location and temporai intensity pattern of conditioned and unconditioned stimuli on the acquisition of conditioned suppression in rats. Journal of Experimental Psychology: Animal Behavior Processes, 1975, 104, 114-121.

Zentall, T. R., \& Hogan, D. E. Keypecking in pigeons produced by pairing keylight with inaccessible grain. Journal of the Experimental Analysis of Behavior, 1975, 23, 199-206.

\section{NOTE}

1. With only four subjects per group, the Wilcoxon signedrank test is insensitive to $\mathrm{p}$ values less than .062 .

(Received for publication November 28, 1978.) 